Roli Purwar*, Anjali Verma and Radhika Batra

\title{
Antimicrobial gelatin/sericin/clay films for packaging of hygiene products
}

https://doi.org/10.1515/polyeng-2018-0406

Received January 18, 2019; accepted June 17, 2019; previously published online July 18, 2019

Abstract: In this study we have prepared flexible gelatin/sericin/clay blend films for packaging applications of hygiene products. Gelatin/sericin (3:1, 1:1 and 1:3 w/w ratios) films were prepared using glutaraldehyde as a crosslinking agent and glycerol as a plasticizer by the solution casting method. The concentrations of gelatin and sericin were optimized on the basis of their mechanical properties. Closite 30B and copper-modified montmorillonite clay (with concentration of $1-5 \%$ ) were incorporated into the optimized gelatin/sericin blend films in order to improve the mechanical and antimicrobial properties. The water vapor transmission rate of the film samples was also studied. The soil burial test showed very good biodegradability of the blends films. The antimicrobial testing revealed efficient activity of these blend films against Gram-positive (Staphylococcus aureus) and Gram-negative (Escherichia coli) bacteria. Hence, on the basis of the above-mentioned properties, these films can be considered as promising candidates for packaging of hygiene maintenance products.

Keywords: antimicrobial; biodegradable; CuMMT; gelatin; sericin.

\section{Introduction}

In the domain of the packaging market, packaging of hygiene-maintaining materials (sanitary napkins, diapers, tissues, pharmaceutical packages, medical equipment like syringes, bio hazardous bags, etc.) is a substantially emerging sector. The principal objectives of packaging are to maintain the safety, wholesomeness

*Corresponding author: Roli Purwar, Department of Applied Chemistry, Delhi Technological University, Shahbad Daulatpur, Bawana Road, Delhi 110042, India, e-mail: roli.purwar@dtu.ac.in, roli.purwar@gmail.com

Anjali Verma and Radhika Batra: Department of Applied Chemistry, Delhi Technological University, Shahbad Daulatpur, Bawana Road, Delhi 110042, India and quality of products from the time of production to the time of utilization. Another important role of packaging is to protect the material from various chemical, physical and biological risks (like light, moisture, gases, microbial contamination, etc.) during the period of storage and distribution [1]. The issues of energy and material cost, regulation on pollutants and disposal of solid waste must also be addressed.

Most of the hygiene maintenance packaging materials that are being developed these days include petroleumbased plastics, i.e. polyethylene, polypropylene, polyester, etc., which have shown excellent physical properties like flexibility and water or air barrier and are cost-effective but have poor degradation properties and are very hazardous to our environment, causing problems associated with their destruction. Research is expanding in this field to facilitate the goal of development of alternative packaging materials, replacing the synthetic ones, that can compete efficiently with the non-degradable analogs. In the recent past, biodegradable polymers have emerged as the best suitable substitutes to target the concerns associated. Also, as far as safety is concerned, packaging materials with antimicrobial activity are gaining the interest of researchers.

Biodegradable packaging material is composed of polymers which can be disintegrated by the action of microorganisms (bacteria, fungi and algae) into natural raw material such as carbon dioxide, water, methane, biomass, etc. [2]. A wide range of biopolymers which are suitable to be utilized as packaging material include polysaccharides, polyhydrides, proteins and lipids such as starch, chitosan, sericin, collagen, gelatin, soy protein, whey protein, etc. [3-5]. However, many of these biopolymers are found to be unsuitable for large-scale industrial packaging due to their poor mechanical and barrier properties [6]. There has been expanding research to improve the physical properties of biopolymer-based films via chemical modifications [7, 8], addition of crosslinking agents [9], addition of neutral fatty acids, lipids, or waxes $[10,11]$ and incorporation of layered silicates $[6,7]$ for several applications including packaging. Recently, research in the field of polymer/layered silicate nanocomposite fibers and films has geared up [12-15]. Incorporation of inorganic nanosized layered silicates into several polymers or polymeric blends has been reported 
to enhance the mechanical properties, water or gas resistance and significant antimicrobial activity in some cases [16-19].

Gelatin, which is derived from collagen, has unique functional properties like gel strength, viscosity, flexibility, gas barrier, antimicrobial activity, etc. So, it is widely used in the food, pharmaceutical, cosmetic and photographic industries [20-23]. Much work has been reported utilizing gelatin along with other biopolymers to enhance the physical and mechanical properties of composite films [24-32]. Nanocomposite films of gelatin with only sodium montmorillonite clay $[33,34]$ and clay along with silver nanoparticles [35] showed better barrier properties, improved tensile strength and strong antibacterial activity, respectively.

Sericin, a globular gummy protein, is a potential biomaterial, which is discarded as waste by silk processing industries. This protein has 18 amino acids and is majorly composed of polar side groups that impart great hydrophilicity and sensitivity toward modifications. Also, it has diverse physiological properties such as biodegradability, non-toxicity, UV resistance and antimicrobial activity [36, 37]. It has been explored enormously in pure form as well as in the modified form as blends or by crosslinking and copolymerizing with other macromolecules for various applications, such as wound dressing, packaging and cosmetics, in different fields [38]. Kundu et al. have reported the fabrication of sericin/gelatin three-dimensional (3-D) scaffolds and 2-D films for tissue engineering applications [39]. Sericin/polyvinyl alcohol (PVA)/clay blend films have been prepared for packaging applications [6].

Gelatin and sericin both possess tremendous physiological properties separately but hold some shortcomings, such as sericin being fragile in the dry sate shows poor flexibility but has antimicrobial activity, and gelatin has no antimicrobial activity in the pure state but can impart great flexibility. Blending these two materials will enhance properties like flexibility, antimicrobial activity along with water and oxygen permeability and mechanical strength. Also, incorporation of a plasticizer and a crosslinker along with nanoclays can boost their properties further. In this study, we have attempted to blend gelatin with sericin using optimized amount of glycerol as plasticizer and glutaraldehyde as crosslinking agent. Optimized concentrations of two nanoclays, namely, copper-modified montmorillonite (CuMMT) and Closite 30B, have been incorporated into the blend films to enhance their mechanical properties as well as antimicrobial activity. Gelatin/sericin blend films are characterized.

\section{Materials and methods}

\subsection{Materials}

Bombyx mori silk cocoons were produced from the Central Silk Research Board, Bahraich, India. Gelatin (bacteriological) was purchased from Thermo Fisher Scientific India Pvt. Ltd., Reagent-grade glutaraldehyde [Central Drug House (P) LTD, New Delhi, India] and glycerol (SRL (P) LTD, New Delhi, India) were used in this study. Closite 30B was procured from Southern Clay USA, and sodium montmorillonite clay was purchased from Sisco Research Laboratories Pvt. Ltd., Maharashtra, India. Distilled water was used for all experiments.

\subsection{Methods}

\subsubsection{Preparation of sericin}

The silk cocoons were cut into very small pieces, and sericin was extracted using the high-temperature highpressure degumming (HTHP) technique [40]. Briefly, aqueous extraction of sericin was carried out by boiling cut cocoons in autoclave at $120^{\circ} \mathrm{C}$ for $1 \mathrm{~h}$, keeping the material-to-liquor ratio at 1:15. The sericin extracted aqueous solution was then filtered with muslin cloth to remove fibroin and other suspended impurities. Solid sericin was obtained by cooling down the sericin solution.

\subsubsection{Preparation of the gelatin/sericin blend films}

Gelatin/sericin (solid weight 10 wt.\%) blend films were prepared by the solution casting method. The aqueous solution of gelatin/sericin in 1:3, 1:1 and 3:1 $(\mathrm{w} / \mathrm{w})$ ratios were prepared in hot water with continuous stirring. Glutaraldehyde (5\%, w/w) and glycerol $(30 \%, w / w)$ were added in the gelatin/sericin solution. These solutions were poured in petri dishes and dried at $40^{\circ} \mathrm{C}$ at least for $24 \mathrm{~h}$. After drying, the films were heat treated at $120^{\circ} \mathrm{C}$ for $1 \mathrm{~h}$. The average thickness of the blend film was $0.25 \pm 0.02 \mathrm{~mm}$. The dry films were stored in plastic bags before all characterization.

\subsubsection{Preparation of the gelatin/sericin/clay blend films}

Aqueous solution containing gelatin/sericin (3:1 w/w ratios), $5 \%(\mathrm{w} / \mathrm{w})$ glutaraldehyde and $30 \%(\mathrm{w} / \mathrm{w})$ glycerol were prepared in hot water. Different concentrations 
of clays ranging from 1 to $5 \%(\mathrm{w} / \mathrm{w})$ were dispersed in the solution. The solution was ultrasonicated for $30 \mathrm{~min}$ and poured in petri dishes. After drying, the films were heat treated at $120^{\circ} \mathrm{C}$ for $1 \mathrm{~h}$. The dry films were stored in plastic bags before all subsequent characterization. The average thickness of the blend film was $0.25 \pm 0.02 \mathrm{~mm}$.

\subsubsection{Mechanical testing}

The mechanical properties of the gelatin/sericin/clay blend films were determined using an Instron Universal Testing Machine (INSTRON model no 3369) running at a crosshead speed of $5 \mathrm{~mm} / \mathrm{min}$ and a gauge length of $50 \mathrm{~mm}$. The samples were cut into $70 \mathrm{~mm} \times 10 \mathrm{~mm}$ rectangular pieces. At least three samples were tested, and their stress-strain curves were recorded.

\subsubsection{Thermal analysis}

The thermal properties of the gelatin/sericin films were analyzed by thermal gravimetric analysis (TGA). TGA measures the change in the mass of a sample as a function of temperature or time in a controlled atmosphere. TGA was done using the TGA4000 (Perkin Elmer). Samples

\subsubsection{Antibacterial testing}

The antibacterial activity of the samples was carried out using the disk diffusion method and was followed by the method described by Purwar et al. with slight modifications [9]. The antimicrobial activity of the gelatin/sericin and gelatin/sericin/clay films was investigated against the growth of Escherichia coli and Staphylococcus aureus bacteria, which were cultured in Miller's Luria broth, followed by incubation in an incubator shaker for $24 \mathrm{~h}$. Bacterial suspension $(20 \mu \mathrm{l})$ was uniformly spread on the sterile petri dishes of Müller-Hinton agar using a sterile spreader, and pieces of antimicrobial films were placed on the bacterial culture. Plates were sealed and incubated at $37^{\circ} \mathrm{C}$ for $24 \mathrm{~h}$. There was no zone of inhibition, but the film surface was free from bacterial growth. After incubation, the samples were placed in a 50-ml sterilized flask containing $10 \mathrm{ml}$ of sterilized distilled water. The flask was shaken for $1 \mathrm{~h}$ at $150 \mathrm{rpm}$ to release the bacteria from the samples. Serial dilutions of inoculants (up to $10^{-5}$ time) were made in the sterilized water. The diluted inoculants were spread on an agar plate, and the plates were incubated at $37^{\circ} \mathrm{C}$ for $24 \mathrm{~h}$. After incubation, the bacterial colonies were counted. The antibacterial activity was calculated using the equation

$$
\text { Antibacterial activity }(\%)=\frac{\text { No of colonies in control plates }- \text { No of colonies in sample plates }}{\text { No of colonies in control plates }} \times 100
$$

were analyzed at a heating rate of $10^{\circ} \mathrm{C} / \mathrm{min}$ in the range of $30-900^{\circ} \mathrm{C}$ under nitrogen atmosphere.

\subsubsection{Water vapor transmission}

The water vapor transport rate of the gelatin/sericin/clay blend films was measured by the method described by Kang et al. with some modifications [41]. The specimens were placed in test containers with anhydrous distilled water, which were placed in a control chamber at a constant temperature $\left(37^{\circ} \mathrm{C}\right)$. Water vapor transmission was calculated from the weight of the test container before and after the test.

$$
\text { WVT (water vapor transmission rate) }=\frac{G}{t A}
$$

where

$G$ : weight change (g)

$t$ : time during which $\mathrm{G}$ occurred (h)

$A$ : test area $\left(\mathrm{m}^{2}\right)$.

\subsubsection{Biodegradability test}

The biodegradable behavior of the gelatin/sericin/clay blend film samples was tested by the method described by Kermani and Esfandiary with some modifications [42]. Briefly, the gelatin/sericin and gelatin/sericin/clay films were cut into $(7 \mathrm{~cm} \times 1 \mathrm{~cm})$ small pieces, weighted and buried into the soil in a pot covered with a plastic net and exposed to atmospheric conditions. The degradation behavior of the films was evaluated by measurement of their weight loss at regular time interval of $48 \mathrm{~h}$.

\section{Results and discussion}

\subsection{Mechanical properties}

\subsubsection{Effect of sericin on gelatin}

The effect of sericin on tensile strength, elastic modulus and elongation at the break of the gelatin/sericin blend 
Table 1: Tensile properties of flexible crosslinked gelatin/sericin films with different blend ratios.

\begin{tabular}{lrrr}
\hline $\begin{array}{l}\text { Sample } \\
\text { (gelatin: } \\
\text { sericin) }\end{array}$ & $\begin{array}{r}\text { Tensile } \\
\text { strength } \\
(\mathrm{MPa})\end{array}$ & $\begin{array}{r}\text { Tensile } \\
\text { modulus } \\
(\mathrm{MPa})\end{array}$ & $\begin{array}{r}\text { Elongation } \\
\text { at break (\%) }\end{array}$ \\
\hline $3: 1$ & $3.12(0.48)$ & $1.02(0.34)$ & $448(8)$ \\
$1: 1$ & $2.31(0.13)$ & $1.06(0.25)$ & $443(6)$ \\
$1: 3$ & $1.53(0.09)$ & $1.25(0.13)$ & $350(9)$ \\
\hline
\end{tabular}

Values given in the brackets show coefficient of variation (CV\%).

Tests were carried out in triplicate.

films is shown in Table 1. It is observed that as content of the sericin in the blend increases from 25 to $75 \%$, the tensile strength and elongation at break decrease, but the tensile modulus slightly increases. The enhanced amorphous structure in the blend films is accountable to the decrease in tensile strength. The increase in tensile modulus and reduced elongation at break with increasing sericin content are due to the brittle nature of sericin. Kundu et al. has reported a similar effect of high sericin content on the compressive strength of sericin-gelatin scaffolds [39]. The results suggest that blend films with higher gelatin percentage (i.e. 75\%) provide bulk mechanical strength to the gelatin/sericin blend films, so films with a gelatin/sericin blend ratio of 3:1 were chosen to be used for further experimentation.

\subsubsection{Effect of nanoclays}

Nanoclays, namely, Closite 30B and CuMMT, used in this study act as antimicrobial agents as well as reinforcing fillers. Closite 30B having quaternary ammonium structure and the presence of $\mathrm{Cu}$ ions in CuMMT are known to offer antibacterial activity. The effect of different concentrations of the nanoclays on the tensile strength, tensile modulus and elongation at the break of the gelatin/ sericin/clay blend films is shown in Tables 2 and 3.

Table 2: Tensile properties of flexible crosslinked gelatin/sericin (3:1) blend films with different concentrations of Closite 30B.

\begin{tabular}{lrrr}
\hline Sample & $\begin{array}{r}\text { Tensile } \\
\text { strength } \\
(\mathrm{MPa})\end{array}$ & $\begin{array}{r}\text { Tensile } \\
\text { modulus } \\
(\mathrm{MPa})\end{array}$ & $\begin{array}{r}\text { Elongation } \\
\text { at break (\%) }\end{array}$ \\
\hline 1\% Closite 30B & $4.64(0.64)$ & $0.99(0.14)$ & $678(13)$ \\
$3 \%$ Closite 30B & $8.10(0.57)$ & $1.50(0.39)$ & $820(21)$ \\
$5 \%$ Closite 30B & $2.37(0.28)$ & $3.17(0.10)$ & $560(8)$ \\
\hline
\end{tabular}

Values given in the brackets show coefficient of variation (CV\%). Tests were carried out in triplicate.
Table 3: Tensile properties of flexible crosslinked gelatin/sericin (3:1) blend films with different concentrations of CuMMT.

\begin{tabular}{lccr}
\hline Sample & $\begin{array}{r}\text { Tensile } \\
\text { strength } \\
(\mathrm{MPa})\end{array}$ & $\begin{array}{r}\text { Tensile } \\
\text { modulus } \\
(\mathrm{MPa})\end{array}$ & $\begin{array}{r}\text { Elongation } \\
\text { at break (\%) }\end{array}$ \\
\hline 1\% CuMMT & $4.23(0.34)$ & $0.63(0.26)$ & $830(24)$ \\
$3 \%$ CuMMT & $2.70(0.48)$ & $0.84(0.05)$ & $632(16)$ \\
$5 \%$ CuMMT & $2.13(0.51)$ & $1.71(0.74)$ & $390(11)$ \\
\hline \multicolumn{4}{l}{ Values given in the brackets show coefficient of variation (CV\%). } \\
\multicolumn{4}{l}{ Tests were carried out in triplicate. }
\end{tabular}

In the case of Closite 30B, as the concentration of the filler increases, the tensile modulus of the blend films increases. The tensile strength and elongation at break increase up to $3 \%$ concentration of clay, and on further increase in concentration it decreases, which can be attributed to lower dispersion and agglomeration of clay in the gelatin/sericin matrix [43]. Similarly, in the case of CuMMT, the film shows high tensile strength, elongation at break and low tensile modulus at $1 \%$ concentration of clay, and as the clay concentration increases tensile strength, elongation at break decreases and tensile modulus increases. The combination of gelatin/ sericin in blend ratio 3:1 with 3\% Closite 30B showed a tensile strength of 8.1 MPa comparable to the low-density polyethylene (LDPE)/starch blend films reported in literature [44]. So, for further testing, optimized samples with 1\% CuMMT and 3\% Closite 30B with gelatin/sericin blend ratio of 3:1 have been used. The gelatin/sericin film without clay has been used as control.

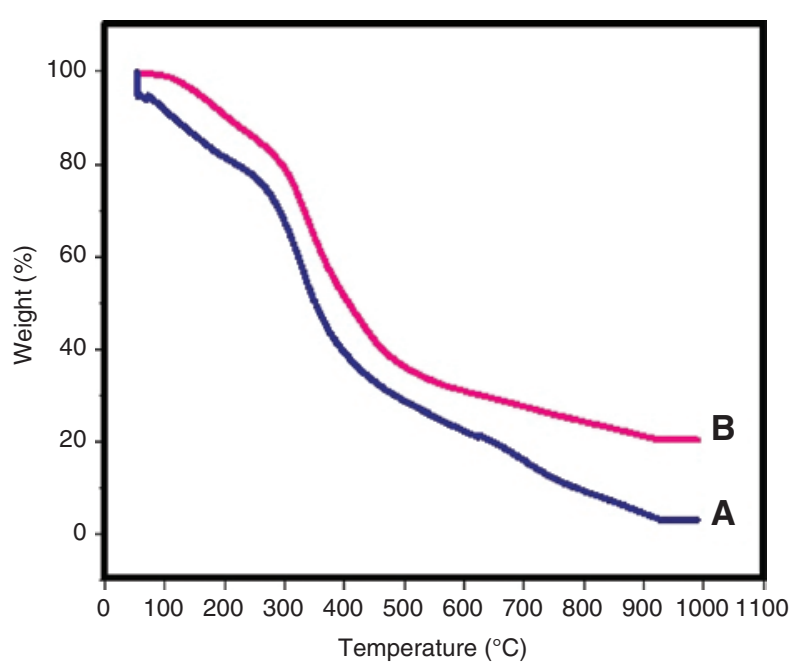

Figure 1: TGA thermograms of the (A) gelatin/sericin film and the (B) crosslinked gelatin/sericin film. 


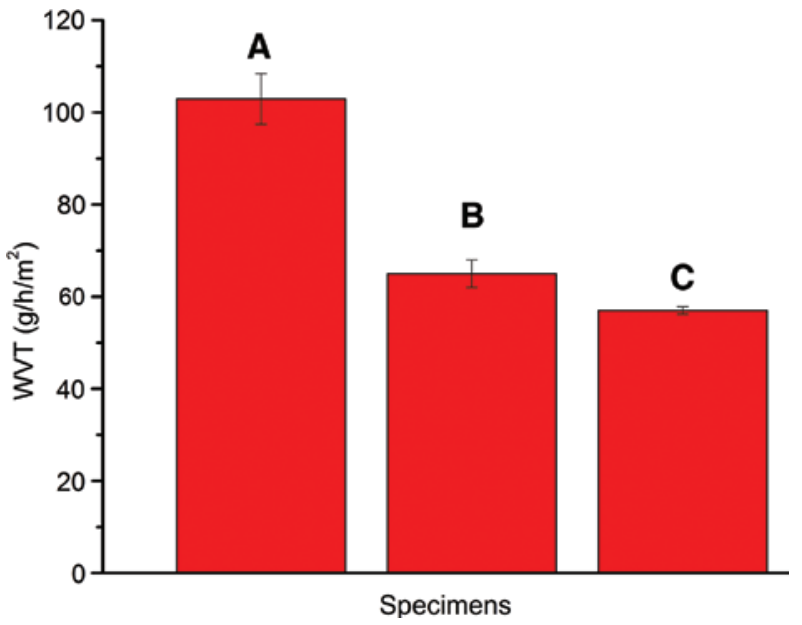

Figure 2: Water vapor transmission of film samples: (A) 3:1 gelatin/ sericin blend film, (B) 3:1 gelatin/sericin blend with 1\% CuMMT and (C) 3:1 gelatin/sericin blend with $3 \%$ Closite 30B. Error bars represent standard deviation in data.

\subsection{Thermal analysis}

TGA thermograms of gelatin/sericin and crosslinked gelatin/sericin films showed multistep degradation. The initial weight loss up to $100^{\circ} \mathrm{C}$ is due to the presence of moisture in gelatin/sericin films. Figure $1 \mathrm{~A}$ shows the thermogram of the gelatin/sericin film with initial degradation temperature of $280^{\circ} \mathrm{C}$, and the film completely degraded at $900^{\circ} \mathrm{C}$ with overall weight loss of $99 \%$, whereas the initial degradation temperature of crosslinked gelatin/sericin film was observed to be $310^{\circ} \mathrm{C}$ with overall weight loss of $80 \%$ as shown in Figure 1B. The enhanced thermal stability, along with reduced overall weight loss, confirms the chemical crosslinking of the gelatin/sericin film in the presence of glutaraldehyde. Packaging applications which require sterlization can make use of these thermally stable blend films.
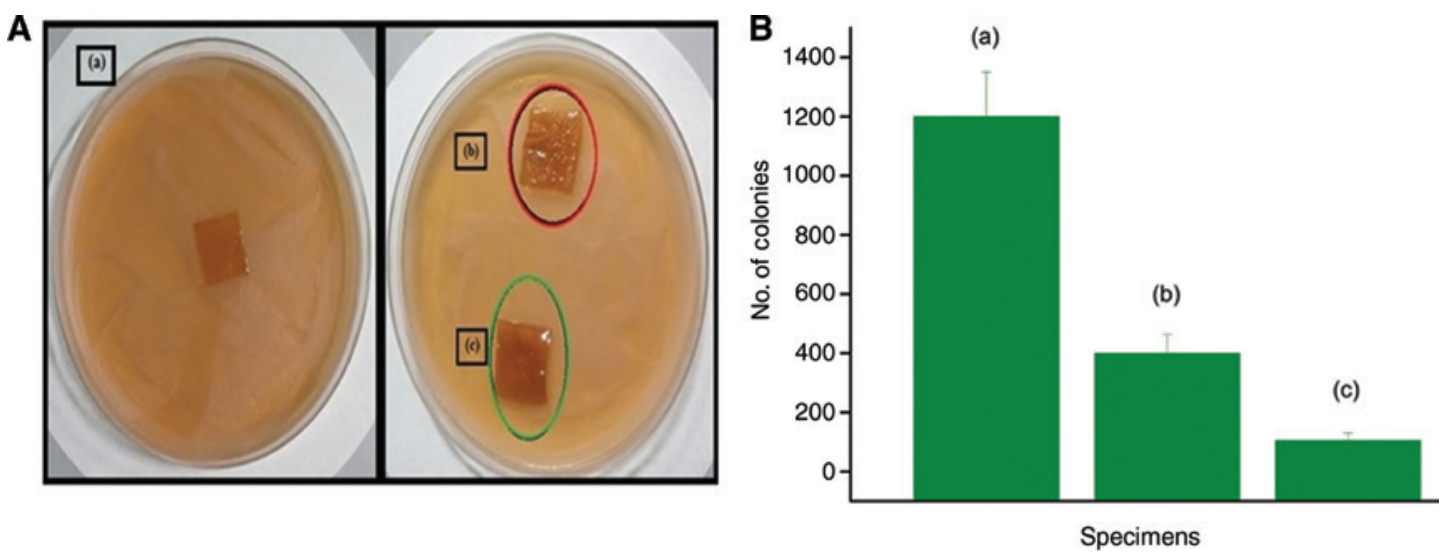

(a)

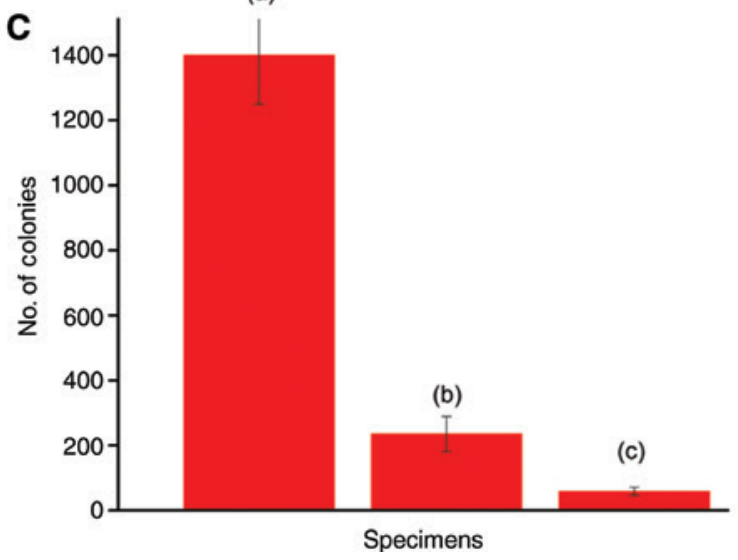

Figure 3: (A) Antibacterial testing of film samples: (a) 3:1 gelatin/sericin blend film, (b) 3:1 gelatin/sericin blend with 1\% CuMMT and (c) 3:1 gelatin/sericin blend with 3\% Closite 30B. (B) Antibacterial activity against Escherichia coli bacteria. Error bars represent standard deviation in data. (C) Antibacterial activity against Staphylococcus aureus bacteria. Error bars represent standard deviation in data. 


\subsection{Water vapor transmission}

The water vapor transmission rates of the gelatin/sericin and gelatin/sericin/clay films are shown in Figure 2. It is observed that incorporation of the clays into film samples significantly reduced the water vapor transmission rate as compared to the control sample. The values observed for the gelatin/sericin control film sample (without clay) is $102.94 \mathrm{~g} / \mathrm{h} / \mathrm{m}^{2}$, which is reduced to 65.00 and $57.00 \mathrm{~g} / \mathrm{h} / \mathrm{m}^{2}$ for the film sample containing 1\% CuMMT and 3\% Closite 30B, respectively. The reduced water vapor transmission of packaging films will help in maintaining the moisture content in the hygiene material being packed. Clay has been reported to reduce the water vapor transmission rate and water vapor permeability in the literature earlier as well. Clays are known to improve barrier property by developing tortuous path, making it more difficult for the vapor molecules to escape the gelatin/sericin blend matrix [17]. Farahnaky et al. have reported similar results showing considerable reduction in water vapor permeability of gelatin nanoclay films [45].

\subsection{Antibacterial testing}

In the disk diffusion method, there was no zone of inhibition observed in the test samples (Figure 3A). The zone of inhibition will be created only when the antibacterial agents are diffused out from the films. In our case, the antibacterial agent such as copper ions and quaternary ammonium ions were not diffusing from the gelatin/ sericin films. Therefore, non-leaching antibacterial test was conducted to study the antibacterial activity of film samples. The antibacterial activity of the films against $E$. coli bacteria and $S$. aureus is shown in Figure $3 \mathrm{~B}$ and $\mathrm{C}$, respectively. As evident from the graph, the growth of $E$. coli bacteria has been reduced by $90.8 \%$ in the sample containing 3\% Closite 30B and by $67 \%$ in sample containing
A

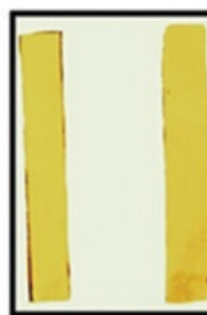

(a)

(b)
Day 1

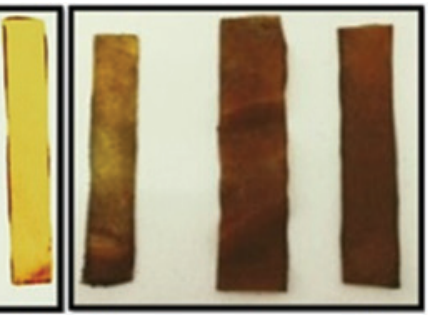

(c) (a) (b) (c) (a)
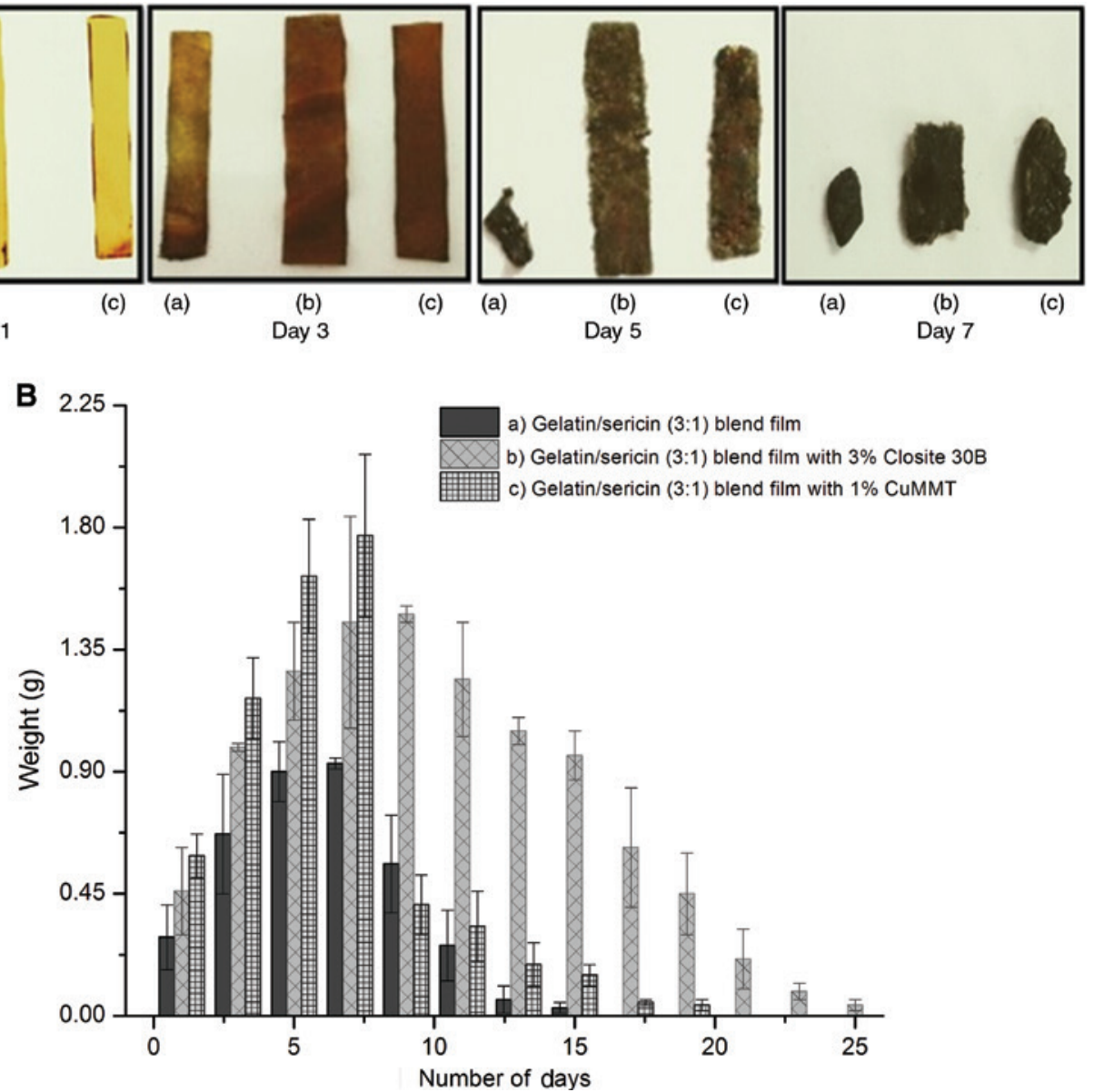

Figure 4: (A) Biodegradability test of samples: (a) 3:1 gelatin/sericin blend film, (b) 3:1 gelatin/sericin blend with 1\% CuMMT and (c) 3:1 gelatin/sericin blend with $3 \%$ Closite 30B. (B) Weight change in the film samples due to biodegradation. Error bars represent standard deviation in data. 
$1 \%$ CuMMT as compared to the control sample containing no clay. Whereas for $S$. aureus, the bacterial growth has been reduced to a greater extent being $94 \%$ in samples with $3 \%$ Closite $30 \mathrm{~B}$ and by $78 \%$ in sample incorporating $1 \%$ CuMMT as compared to the control sample. The significant reduction in bacterial growth suggests that the film samples show antibacterial activity through the barrier/ non-leaching mechanism [9]. Sericin itself has been reported to show antibacterial property $[46,47]$. The addition of clay to the sample further enhances the antimicrobial activity of the material. Abreu et al. have reported the antimicrobial effect of Closite $30 \mathrm{~B}$ against bacteria due to the release of ammonium salts from the nanoclay, which affects the bacteria-sensitive targets [48]. On the other hand, copper ion present in the modified copper clay has been shown to obstruct the metabolic activity of bacteria via entering its bacterial cell, causing toxic effect [49].

\subsection{Biodegradability test}

In the soil burial test, it is observed that both the gelatin/ sericin and gelatin/sericin/clay film samples initially swell by absorbing the moisture present in the soil and after a few days lose weight, implying that degradation begins. Figure $4 \mathrm{~A}$ shows the images of the biodegradation of film samples. As shown in Figure 4B, the extent of swelling in the samples incorporating clays is greater as compared to the one without clay; this is due to the high hydrophilic nature of clays used. Also, the degradation of the gelatin/sericin matrix occurs faster in comparison to gelatin/sericin/clay films; this means that higher concentration of clay reduces the degradation process. The weight loss occurs due to the adhering of soil particles to the film surface [50].

\section{Conclusion}

The blend ratio of gelatin/sericin was optimized. The 3:1 blend ratio showed the best mechanical properties. The mechanical strength was further enhanced by the addition of clay. The gelatin/sericin blend films containing 3\% Closite 30B showed tensile strength of $8.1 \mathrm{MPa}$, which is comparable to the biodegradable LDPE/starch blend films being used commercially. The films show good antibacterial properties against selected bacteria, however retaining their biodegrability. These flexible gelatin/sericin/clay films can be an impending replacement to the hazardous packaging options currently available.
Acknowledgements: The authors acknowledge the Department of Applied Chemistry, Delhi Technical University for providing the financial support and research facilities.

\section{References}

[1] Marsh K, Bugusu B. J. Food Sci. 2007, 72, R39-R55.

[2] Hanani ZAN, Roos YH, Kerry JP. Int. J. Biol. Macromol. 2014, 71, 94-102.

[3] Liu L, Kerry JF, Kerry JP. Int. J. Food Sci. Technol. 2006, 41, 295-302.

[4] Cuq B, Gontard N, Cuq JL, Guilbert S. Mol. Nutr. Food. Res. 1998, 42, 260-263.

[5] Cuq B, Gontard N, Cuq JL, Guilbert S. J. Food Sci. 1995, 60, 1369-1374.

[6] Purwar R, Goutham KS, Srivastava CM. Fiber. Polym. 2016, 17, 1206-1216.

[7] Wang Z, Zhang Y, Zhang J. Sci. Rep. 2014, 4, 7064.

[8] Liu Y, Park M, Ding B, Kim J, El-Newehy M, Al-Deyab SS, HakYong K. Fiber. Polym. 2015, 16, 629-633.

[9] Purwar R, Sharma S, Sahoo P, Srivastava CM. Fiber. Polym. 2015, 16, 761-768.

[10] Baldwin EA, Nisperos-Carriedo NO, Baker RA. Crit. Rev. Food Sci. Nutr. 1995, 35, 509-524.

[11] Cutter CN. Meat Sci. 2006, 74, 131-142.

[12] Pavlidou S, Papaspyrides CD. Prog. Polym. Sci. 2008, 33, 1119-1198.

[13] Mittal V. Materials 2009, 2, 992-1057.

[14] Sorrentino A, Gorrasi G, Vittoria V. Trends Food Sci. Technol. 2007, 18, 84-95.

[15] Parida UK, Nayak AK, Binhani BK, Nayak PL. J. Biomater. Nanobiotechnol. 2011, 2, 414-425.

[16] Joshi M, Biswas D, Sarvanan A, Purwar R, Mukhopadhaya R. J. Apply. Polym. Sci. 2011, 125, E224-E234.

[17] Joshi M, Banerjee K, Prasanth R. Ind. J. Fibre Text. Res. 2006, 3, 202-214.

[18] Hong SI, Rhim JW. J. Nanosci. Nanotechnol. 2008, 8, 5818-5824.

[19] Nigmatullin R, Gao F. J. Mater. Sci. 2008, 43, 5728-5733.

[20] Howe AW. Curr. Opin. Colloid Interface Sci. 2000, 5, 288-300.

[21] Djagny KB, Wang Z, Xu S. Crit. Rev. Food Sci. Nutr. 2001, 41, 481-492.

[22] Ulubayram K, Nur Cakar A, Korkusuz P, Ertan C, Hasirci N. Biomaterials 2001, 22, 1345-1356.

[23] Wang T, Zhu XK, Xue XT, Wu DY. Carbohydr. Polym. 2012, 88, 75-83.

[24] Wang L, Auty MAE, Kerry JF, Kerry JP. J. Food Eng. 2009, 90, 11-19.

[25] Pérez-Mateos M, Montero P, Gómez-Guillén MC. Food Hydrocolloids 2009, 23, 53-61.

[26] Sionkowska A, Wisniewski M, Skopinska J, Kennedy C], Wess TJ. Biomaterials 2004, 25, 795-801.

[27] Yin Y, Li Z, Sun Y, Yao K. J. Mater. Sci. (Lett.) 2005, 40, 46494652.

[28] Celis D, Azocar MI, Enrione J, Paez M, Matiacevich S. Proc. Food Sci. 2011, 1, 399-403.

[29] Zhuang H, Zheng JP, Gao H, De Yao K. J. Mater. Sci. Mater. Med. 2007, 18, 951-957. 
[30] Chiono V, Pulieri E, Vozzi G, Ciardell G, Ahluwalia A, Giusti P. J. Mater. Sci. Mater. Med. 2008, 19, 889-898.

[31] Pereda M, Ponce AG, Marcovich NE, Ruseckaite RA, Martucci JF. Food Hydrocolloids 2011, 25, 1372-1381.

[32] Gómez-Estaca J, López de lacey A, López-Caballero ME, GómezGuillén MC, Montero P. Food Microbiol. 2010, 27, 889-896.

[33] Bae HJ, Park HJ, Hong SI, Byun Y], Darby DO, Kimmel RM, Whiteside WS. LWT Food Sci. Technol. 2009, 42, 1179-1186.

[34] Shakila RJ, Jeevithan E, Varatharajakumar A, Jeyasekaran G, Sukumar D. Food Chem. 2012, 135, 2260-2267.

[35] Kanmani P, Rhim JW. Food Hydrocoll. 2014, 35, 644-652.

[36] Aramwit P, Siritientong T, Srichana T. Waste Manag. Res. 2011, 30, 217-224.

[37] Padamwar MN, Pawar AP. J. Sci. Ind. Res. 2004, 63, 323-329.

[38] Rajput SK, Singh MK. J. Polym. Text. Eng. 2015, 2, 29-35.

[39] Mandal BB, Priya AS, Kundu SC. Acta Biomaterialia 2009, 5 , 3007-3020.

[40] Gulrajani ML, Purwar R, Prasad RK, Joshi M. J. Appl. Polym. Sci. 2009, 113, 2796-2804.
[41] Kang YK, Park CH, Kim J, Kang TJ. Fiber. Polym. 2007, 8, 564-570.

[42] Kermani AS, Esfandiary N. Adv. Nanoparticles 2016, 5, 18-26.

[43] Eng CC, Ibrahim NA, Zainuddin N, Ariffin H, Yunus WMZW, Then YY. Int. J. Polym. Sci. 2014, 2014, 1-8.

[44] Raj B, Sankar U, Siddaramaiah. Adv. Polym. Techn. 2004, 23, 32-45.

[45] Farahnaky A, Dadfar SMM, Shahbazi M. J. Food Eng. 2014, 122, 78-83.

[46] Divya J, Srinivasan J, Manohari BG. Int. J. Pharm. Biol. Sci. 2016, 7, 113-119.

[47] Savitha C, Satheeswaran B. Int. J. Ext. Res. 2015, 1, 1-4.

[48] Abreua AS, Oliveira M, de Sáa A, Rodrigues RM, Cerqueira MA, Vicente AA, Machadoa AV. Carbohydr. Polym. 2015, 129, 127-134.

[49] Yao DW, Yu ZZ, Li N, Hou YN, Xu JR, Yang DJ. J. Zhejiang Univ. SC B 2016, 17, 1-9.

[50] Priya B, Gupta VK, Pathania D, Singha AS. Carbohydr. Polym. 2014, 109, 171-179. 